\title{
DEVELOPMENT AND TESTING OF A CAPACITIVE DIGITAL SOIL MOISTURE
}

\section{METRE}

\author{
K. N. Ogbu', E. L. Ndulue ${ }^{2}$, V. Ogwo ${ }^{3, *}$ and C. C. Mbajiorgu ${ }^{4}$ \\ 1DEPT. of AGRIC. AND Bioresources EnGINEERING, NNAMdi AZIKIWE UniV., AWKA, ANAMBRA STATE. NIGERIA \\ 2,3,4DEPT. OF AGRicultural AND BIORESOURCES ENGINEERING, UNIV. OF NigERIA, NSUKKA, ENUGU STATE. NIGERIA \\ E-mail addresses: ${ }^{1}$ kn.ogbu@unizik.edu.ng, ${ }^{2}$ emeka.ndulue@unn.edu.ng, ${ }^{3}$ vintus.ogwo@unn.edu.ng, \\ ${ }^{4}$ constantine.mbarjiorgu@unn.edu.ng
}

\begin{abstract}
This paper presents a low cost, simple digital soil moisture meter, working on the principle of dielectric. A digital soil moisture meter using the NE555 timer and micro controller as a major electronic component was developed and tested, which display its output in a range of 0.0 to $99 \%$ on the 7-segment displayed unit. The digital soil moisture meter developed was compared with gravimetric method for soil moisture determination on fifteen soil samples added different level of water during calibration process. The results revealed a relatively linear relationship between the moisture content process and the digital soil moisture meter. The regression coefficient $\left(R^{2}\right)$ of the digital soil moisture meter calibration was 0.984 . Twenty soil samples were used in validation of the calibrated digital soil moisture meter. The regression coefficient $\left(R^{2}\right)$ was found to be 0.964 , showing validity of the developed digital soil moisture meter. The developed meter provided up to $96 \%$ accuracy in estimating the value of the soil moisture content. The results showed that the developed digital soil moisture meter is more reliable, sensitive, precise and easy to use.
\end{abstract}

Key Words: Soil moisture content, Metre, Capacitance sensor, Microcontroller, Dielectric

\section{INTRODUCTION}

While the soil system provides anchorage for roots and fundamental to crop growth, water is one of the most important components of plant growth. Soil moisture affects crop growth, seed development, root development and agricultural production. In fact, [1], described water as the important requirement for agricultural production and its needs cannot be overemphasized. However, it is important that the right quantity and quality of water should be supplied to the crop at the right time. It goes beyond just water application. Over and under irrigation have its own attendant consequences which affect yield to a great extent.

As plant grows, it uses up the water within the soil profile of its root zone. As the water is being used by the plants, the moisture in the soil eventually reaches a level at which irrigation is required or else, plant will experience stress. The processes of depletion and replenishment of soil moisture is very important because it affects plant growth, hence yield and production. The maximum amount of moisture that can be stored in soil and the degree of dryness to which plants can reduce the moisture content of soil are the limits that determine the range of moisture available to plants.

Measuring soil moisture is important in agriculture because it helps farmers manage their irrigation systems more efficiently, develop better irrigation scheduling program and implement water conservation techniques. Not only are farmers able to generally use less water to grow crops, they are able to increase yields and the quality of the crop by better management of soil moisture during plant growth stages. Since the amount and status of water in soils impact crop growth and fate of agricultural chemicals applied to the soil, this requires reliable technique to perform accurate soil water content measurements with minimal soil disturbance. Several methods and devices for measuring moisture content of soil exist. One technique is the capacitive sensor that works on the principle of measuring the dielectric constant. 
Capacitive sensing method corrects the problem of the resistive sensing method. The resistive sensor is prone to corrosion of its probe and its readings are greatly affected by soil acidity and salinity [2]. Also, it is easy, simple and economical to design. Because of these benefits, capacitive sensor techniques are applied in precision agriculture [3]. The aim of this study is to develop and test a digital soil moisture meter. Other specific objectives include to (i) develop a digital soil moisture meter using the principle of capacitance (ii) calibrate the developed digital soil moisture meter using gravimetric method of soil moisture determination and (iii) validate the soil moisture meter using soil samples obtained from Agric. and Bioresources Engineering experimental farm plot, Nnamdi Azikiwe University, Awka, Nigeria.

\section{LITERATURE REVIEW}

\subsection{Soil Moisture Measurement Methods}

Since soil moisture is dynamic, knowledge on changes in soil moisture content from time to time is important for proper monitoring of water management practices both in irrigated and rain fed farming. The laboratory methods of measuring soil moisture content are gravimetric method, volumetric method and potential method. Gravimetric method, also known as oven dry method is the most widely used technique for moisture content determination, as it is simple and well understood. Volumetric moisture content is most commonly used in irrigated agriculture as the reported figures can readily be converted to volumes of water required for optimum growth. With the development of electronic instrumentation for soil moisture determination, the volumetric basis of soil moisture measurement is now the most utilized of the methodologies [4]. The field methods of measuring soil moisture content employ instruments for accurate measurement. These include tensiometer, electrical resistive method, gypsum block, neutron moisture meter and capacitive meter etc. The aim of these alternative methods is either to provide a fast measurement value or to provide values for continuous measurements over longer periods (gypsum block conductivity, tensiometers, thermal conductivity). These approaches need calibration for individual soils if absolute values are actually needed, and they can have a restricted linearity at high or very low moisture ranges [5].

The choice of instrument for soil moisture content determination depends on one or more of the following factors such as: physical limitations of different techniques; the level of information required (either an absolute or relative moisture measurement); the amount of data needed to objectively decide upon an irrigation regime (with consideration to spatial and temporal problems); the initial cost of the instrument and sampling; the reliability of the instrument and the collected data; and, the ease of use of the instrument in the field, and other factors which include: temperature changes, soil salinity and soil acidity [6].

\subsection{Capacitive Soil Moisture Sensor}

A capacitive soil sensor operates on the principle of dielectric, and basically consists of a pair of electrodes which form a capacitor with the soil acting as the dielectric in between. The two electrodes, together with the soil as a dielectric material, form a capacitor. Generally, the higher the water content, the higher the capacitance. So by measuring the capacitance, we can infer the water content in soil. There are many ways to measure capacitance, which include using the capacitor's reactance to form a voltage divider, creating an RC oscillator where the frequency is determined by the capacitance or by measuring the capacitance by charging the capacitor and detecting the charge time. In this work, the RC oscillator was employed. This capacitor works with the oscillator to form a tuned circuit, and changes in soil water content are detected by changes in the operating frequency.

Capacitance (C) is defined as the amount of charge (Q) required to increase the voltage $(\mathrm{V})$ by one volt between two plates separated by a known distance containing an insulating material and is calculated using

$$
C=\frac{Q}{V}
$$

where Capacitance $C$, is measured in Farads and voltage $\mathrm{V}$, is in volt

A high frequency transistor oscillator (generally $\sim 150$ $\mathrm{MHz}$ ) operates with the soil (dielectric) forming part of an ideal capacitor as shown in the Equation below:

$$
C=E_{r} \frac{E_{o} A}{d}
$$

$E_{r}$ is the relative static permittivity (sometimes called the dielectric constant) of the material between the plates (for a vacuum, $E_{o}=1$ ), $E_{o}$ is the electric constant $\left(E_{o} \sim 8.854 \times 10^{-2} \mathrm{~F}^{-m^{-1}}\right)$ [7], $\mathrm{d}$ is the separation between the plate, $(\mathrm{m})$.

The relationship between $C$ and frequency (F, measured in $\mathrm{Hz}$ ) is dependent on the operating design 
of the capacitance probe. For a down-hole sensor, [8] gave the relationship as:

$$
F=\frac{1}{2 \pi \sqrt{L C}} \sqrt{\left(\frac{1}{C}+\frac{1}{C_{b}}+\frac{1}{C_{c}}\right)}
$$

Where $L$ is the inductance of the oscillator; $C$ is the measured capacitance of the sensor elements; $C_{b}$ is the base capacitance; and $C_{c}$ is the collector capacitance of the oscillator circuit. Equation (3) may be simplified by combining the soil component capacitance and other constants to form:

$$
F=\frac{1}{2 \pi \sqrt{L C}}
$$

\section{MATERIALS AND METHODS}

\subsection{Capacitance Soil Moisture Meter Design Components}

The components used in this work include capacitors, resistors, wires, seven-segment displays, NE555 timer circuit and 89S52 micro controller. Fig. 1 shows the system block diagram of a digital soil moisture meter.

\subsubsection{Capacitance Sensor/Probe}

The sensor is made up of two probe wires separated by small definite distance that enables it to measure the soil moisture capacitance and feed it into the NE555 timer circuit to give it a definite corresponding frequency that is always directly proportional to the soil moisture content. The sensor capacitance increases as the water content of the soil increases. This increase will result to decrease in the designed frequency of the oscillator, which will enable the micro controller to detect the value of soil moisture content that correspond to each of the possible frequencies to be detected.

\subsubsection{NE555 Timer Circuit/ Oscillator}

The NE555 timer circuit is used as an oscillator that pick the capacitor sensor signal for the entire micro controller based circuit. By default, the oscillator operates in astable mode switching a low (-ve) and a high (+ve) outputs repeatedly. The frequency of the astable oscillator switching is dependent on the value of the resistors and the capacitors connected to the astable oscillator circuit. Thus, the capacitive sensor is the major capacitor in this circuit that actively determines the frequency of the oscillator. It is this frequency of the repeated negative and positive current outputs that the microcontroller detects to determine the soil moisture content that must have given rise to it.

\subsubsection{Transistor Amplifier}

This is a small bit Bipolar Junction Transistor (BJT) used to amplify the current output from NE555 oscillator circuit. It is actually a PNP type of the BJT. Generally, the PNP transistors receive negative current to their base terminal while receiving positive DC current to their emitter terminal to enable them switch out that positive DC current from the emitter terminal to the collector terminal (i.e. the $3^{\text {rd }}$ transistor pin/leg that was formerly hanging internally). So each time the PNP BJT receives a negative current from the pin3 out of the NE555 timer oscillator circuit (or even from a transistorized oscillator using two NPN transistor without the NE555 or even from any other type of oscillator), the PNP will switch ON (since it has a constant positive current at its emitter) thus switching that positive current from its emitter to its collector. At that same frequency of the incoming positive current to its base, it will switch a higher positive current from its emitter to collector so that the microcontroller shall receive a repeated higher positive current of the same frequency at its port 3.7 (i.e. pin 17 of the $89 S 52$ microcontroller).

\subsubsection{S52 Microcontroller}

This chip is a member of the 8051 family of microcontrollers. It has a total of 40 pins arranged in 20 by 20 DIP (Dual in Package) structure. It has internal registers (like 128 general purpose registers), EEPROM, ROM, RAM, Processor, arithmetic and logic unit, data buses, CPU, two internal timers, instruction set that is in a hexadecimal format (study from its data sheet).

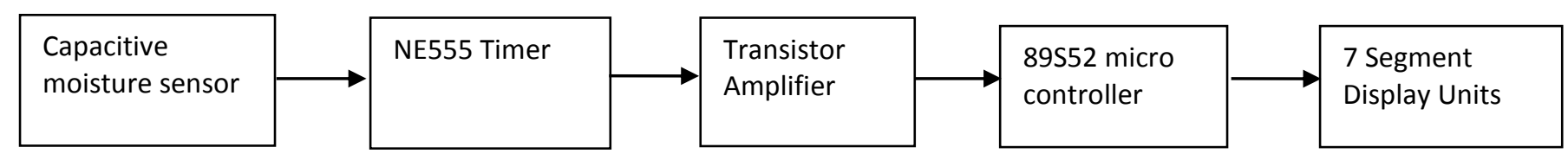

Fig. 1: System Block Diagram. 
Its data exist as bytes like $00000000 \mathrm{~B}$ to $11111111 \mathrm{~B}$ (which is 0 to $255 \mathrm{D}$ which $00 \mathrm{H}$ to $0 \mathrm{FFH}$ in hexadecimal format which is chiefly used in the hexadecimal file that is loaded into the microcontroller by the computer based external chip programmer to instruct the micro controller on how to behave or operate at any condition). Different programming languages (like Assemble, $\mathrm{C}, \mathrm{C}++$, VB. Net, Java, Android, Arduino, etc.) can be used in different compilers or GUI interfaces to generate the same hex file for programming the microcontrollers on how to standalone and operate complexly.

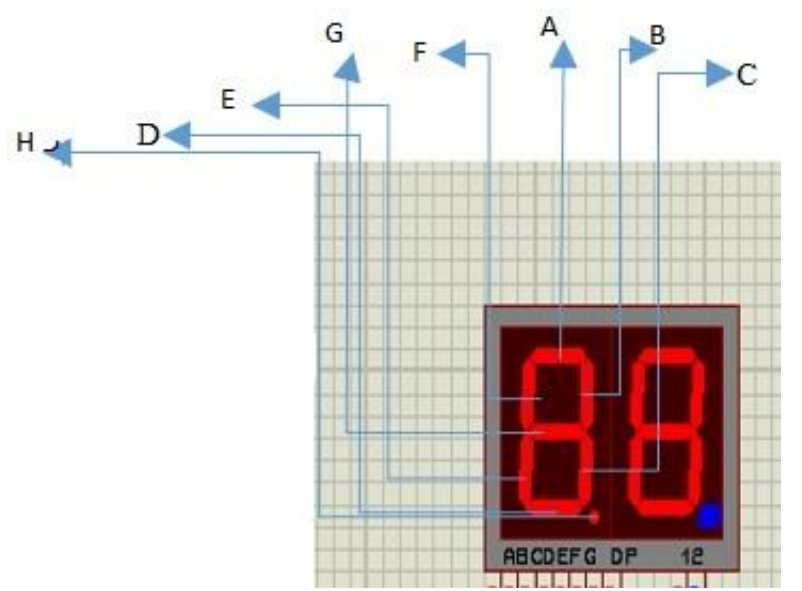

Fig. 2: Double Seven-Segment Display Unit with the $8^{\text {th }}$ $L E D$

In this design, the 89S52 Microcontroller repeatedly scans its port 3.7 for the changing presence of frequency signal/ the positive current from PNP transistor amplifier that is driven by the NE555 timer oscillator. It checks how many frequency signal changes from 1 to 0 in a second on port 3.7. The detected frequency is matched to some internal calibration data to know the soil moisture value that must have given rise to that frequency data/ signal value per second being detected. Then the microcontroller displays the decimal representation of that soil moisture value via its port on the 7 segment display units.

\subsubsection{Seven-Segment Display Units}

This is double/two in one 7 segment display unit. Each one is made of majorly 7 segment arrangement of 7 light emitting diodes (LED) with an additional $8^{\text {th }}$ LED for switching $\mathrm{ON}$ the dot for displaying numbers from
0.0 to 99 . Each of the 7 segment display unit has the positive terminal of its $8^{\text {th }}$ LEDs joined to one common positive terminal. So the 2 in 1 display unit has two separate common anodes but they share the same 8 data bus of which one wire of that data bus connects the negative of LED " $A$ " of the $1^{\text {st }} 7$ segment to negative of LED " $A$ " of the $2^{\text {nd }} 7$ segment. And another pin of the data bus connect the negative of LED " $\mathrm{B}$ " of the $1^{\text {st }} 7$ segment to the negative of LED " $B$ " of the $2^{\text {nd }}$ 7 segments etc.

Only LED H is circular but other LEDs " $A$ " to "G" are block form so that they can represent numbers from 0 to 99. For instance, if all the LEDs " $\mathrm{A}$ " to " $\mathrm{H}$ " receive negative current to the hanging pins, they will all switch ON to form eight (8) as shown in Fig. 2 But if only LED "G" and " $\mathrm{H}$ " are OFF, others will switch ON to form zero (0) and so on.

\subsection{Circuit Design of the Digital Soil Moisture Meter}

The circuit diagram of the digital soil moisture meter is shown in Fig. 3. The 555 timer is operated in the astable mode. The circuit is powered by a 9-Volt battery which powers the voltage regulator to power the whole circuit. The probes of the meter are inserted into the soil to determine the moisture content. Due to conductivity of the soil the insertion of the probes causes the timer to oscillate at a frequency that is proportional to the available moisture content of the soil. This oscillation is visually indicated by the lightemitting diodes (LEDs) that are connected to the output of the timer. When the soil contains more moisture the LEDs blinks faster and the meter indicates a value on the 7 segment displayed unit. When the moisture content is low the blinking reduces. The output signal from timer clocks the transistor which clocks into the microcontroller and then detects the value which is displayed on a 7 segment displayed unit. For each measurement, the probes are inserted into the soil at a constant distance between them. When the probe is inserted into the soil the meter will read values from 0.0 to 99 (\%) depending on the soil moisture content. The circuit of the digital soil moisture meter was developed and packaged as shown in the Fig. 4 below. 


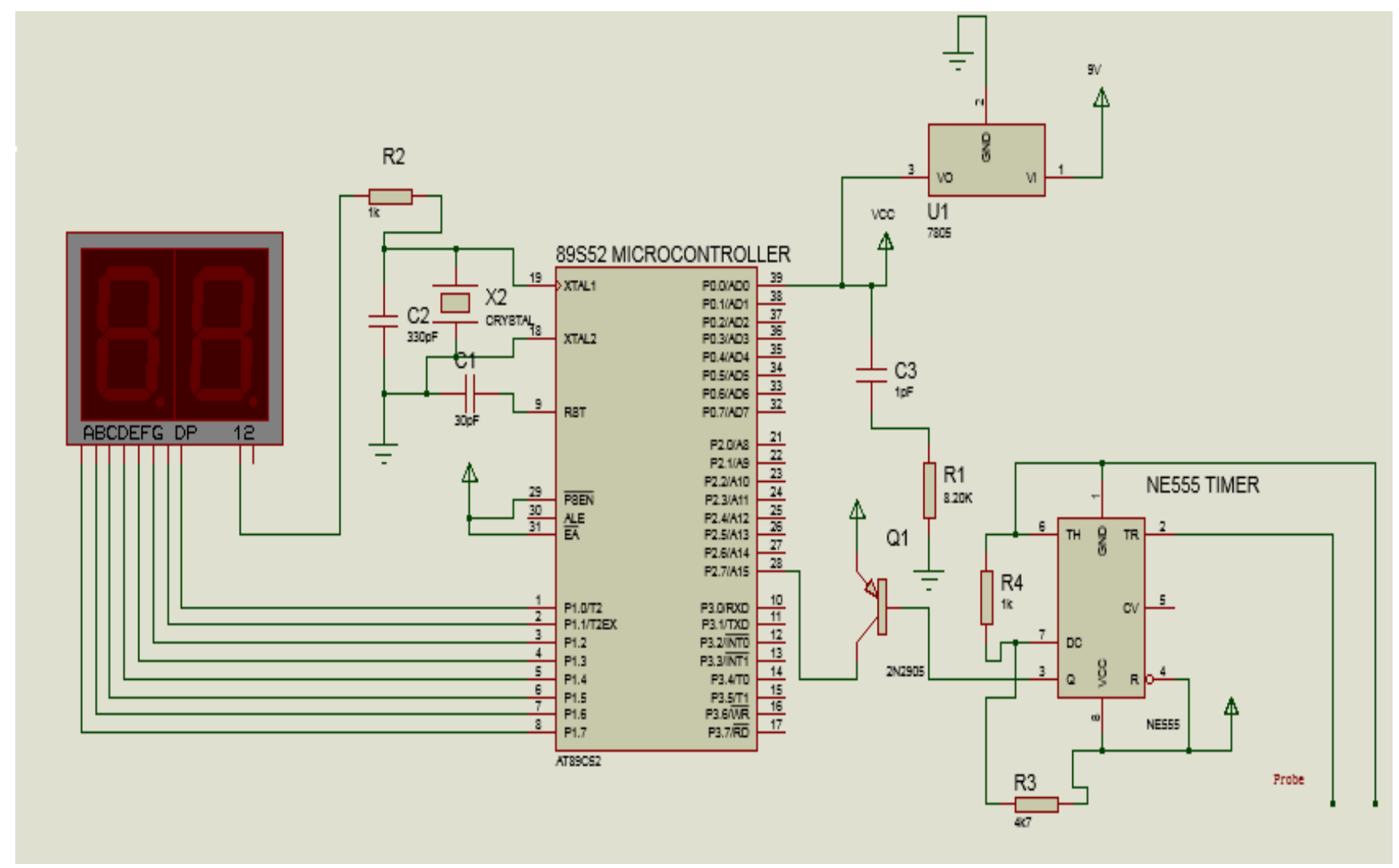

Fig. 3: Circuit Diagram of the Digital Soil Moisture Meter.

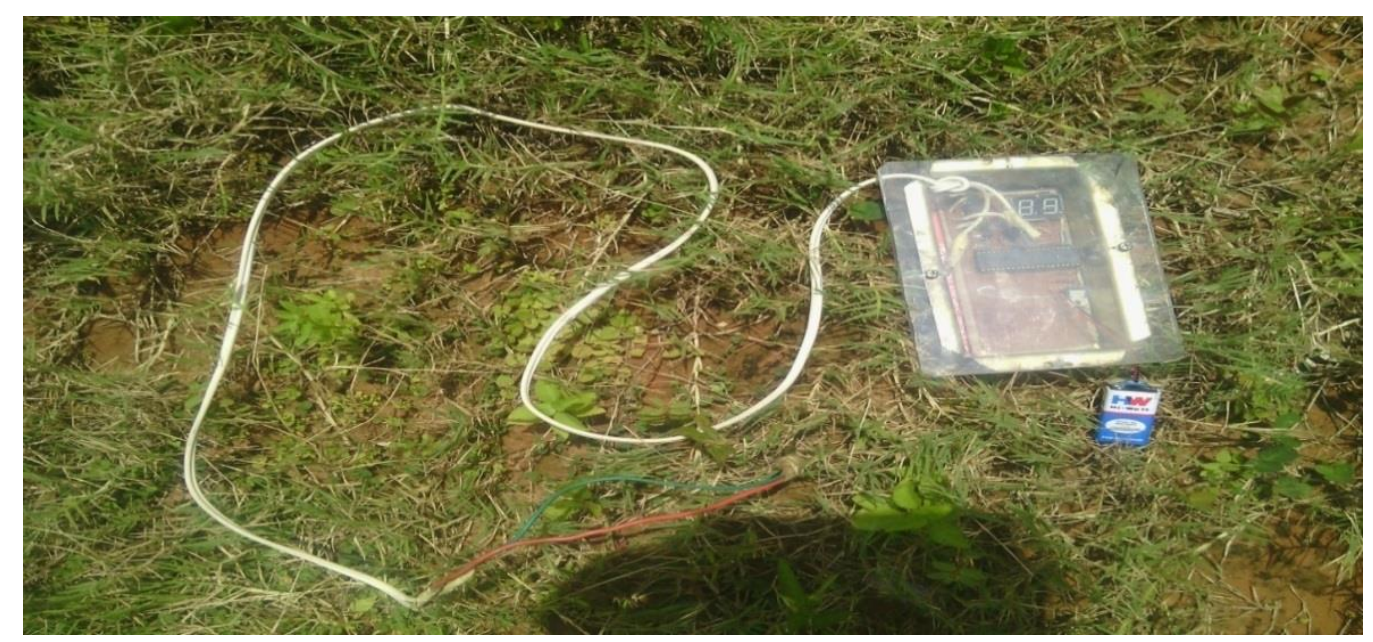

Fig. 4: The Assembled Digital Soil Moisture Meter

Table 1: Calculations for oven dry method of soil moisture determination

\begin{tabular}{cccccccc}
\hline SAMPLES & $\mathrm{A}$ & $\mathrm{B}$ & $\mathrm{C}$ & $\mathrm{D}$ & $W_{m s}$ & $W_{\text {os }}$ & $\mathrm{P}_{\mathrm{mc}}(0 \%)$ \\
\hline 1 & 0.5 & 14.01 & 64.67 & 64.01 & 50.66 & 50 & 1.3 \\
2 & 1 & 15.11 & 66.03 & 65.1 & 50.92 & 49.99 & 1.8 \\
3 & 1.5 & 17.12 & 68.75 & 64.30 & 51.63 & 49.97 & 3.2 \\
4 & 2 & 14.31 & 66.37 & 64.30 & 52.06 & 49.99 & 3.9 \\
5 & 2.5 & 15.08 & 67.56 & 65.02 & 52.48 & 49.98 & 4.7 \\
6 & 3 & 17.37 & 70.25 & 52.88 & 52.88 & 49.97 & 5.4 \\
7 & 3.5 & 15.16 & 69.33 & 65.13 & 54.17 & 49.97 & 7.7 \\
8 & 4 & 14.58 & 69.59 & 64.50 & 55.01 & 49.98 & 9.1 \\
9 & 4.5 & 14.64 & 70.50 & 64.63 & 55.86 & 49.99 & 10.5 \\
10 & 5 & 14.88 & 71.69 & 64.87 & 49.99 & 49.99 & 11.9 \\
11 & 5.5 & 14.35 & 72.91 & 64.25 & 57.63 & 49.98 & 13.2 \\
13 & 6 & 14.35 & 72.91 & 64.25 & 58.56 & 49.99 & 14.6 \\
14 & 6.5 & 14.28 & 74.28 & 64.28 & 60.00 & 49.96 & 16.2 \\
\hline
\end{tabular}




\subsection{Capacitance Soil Moisture Calibration Using Gravimetric Method}

The gravimetric method also known as oven dry method of soil moisture determination is the standard for the calibration of all other soil moisture determination techniques [9]. The purpose of calibration is to establish the specific relationship between the soil moisture obtained from the laboratory (gravimetric method of soil moisture determination) and the readings of the digital soil moisture measuring instrument. It is important to calibrate equipment for different depth of soil.

Moisture content is determined using the equation below

$$
P_{m c}=\frac{W_{m s}-W_{o s}}{W_{m s}} \times 100
$$

In equation (5) $\mathrm{P}_{\mathrm{mc}}$ is the percentage moisture content of soil sampleW $\mathrm{W}_{\mathrm{ms}}$ is the weight of moist soil sample and $\mathrm{W}_{\mathrm{os}}$ is the weight of oven-dry soil sample.

\subsection{Statistical Analysis}

The regression coefficient $\left(\mathrm{R}^{2}\right)$ was used to evaluate the relationship between the oven dry moisture content and the digital soil moisture content. In statistics, $\mathrm{R}^{2}$ indicates how well data points fit a line or curve and was calculated according to equation (6):

$$
R^{2}=\frac{\sum_{i}\left(D_{i}-f_{i}\right)^{2}}{\sum_{i}\left(D_{i}-\bar{D}\right)^{2}}
$$

where $D_{i}$ is the digital soil moisture content values, $\bar{D}$ is the means of the digital soil moisture content values; and $f_{i}$ is the value predicted by the linear regression equation between the digital soil moisture content values, $D_{i}$ and the oven dry moisture content, $O_{i}$

\section{RESULTS AND DISCUSSION}

\subsection{Instrument Calibration}

Soil sample at a depth of $10 \mathrm{~cm}$ was collected using hand auger from Agric and Bioresources Engineering experimental farm plot. The collected wet soil sample was then oven dried (i.e. $\mathrm{P}_{\mathrm{mc}}=0 \%$ ) according to the recommended procedure. $50 \mathrm{~g}$ of the soil sample was measured out with an electrically-powered electronic weighing scale. $0.5 \mathrm{ml}$ of distilled water was added to the dry soil sample incrementally. For each increment, the soil moisture content (\%) was calculated using equation (5) as shown in Table 1 . Subsequently, the developed digital soil moisture meter was used to obtain the probe readings of the moisture content of the soil sample.

In Table $1, A$ is the Quantity of water added, $B$ is the Weight of can, $C$ is the Weight of can + weight of wet sample, $D$ is the Weight of oven dry sample + weight of can, $W_{m s}$ is the Weight of can + weight of wet sample - weight of can, $W_{o s}$ is the Weight of can + weight of oven dry sample - weight of can and:

$$
P_{m c}=\frac{W_{m s}-W_{o s}}{W_{m s}} \times 100
$$

Table 2 shows the digital soil moisture meter readings and oven dry moisture contents of Soil Samples, which was used for calibration of the developed digital soil moisture meter using an assemble language code to reprogram the microchip of the instrument. The oven dry moisture content was plotted against the readings obtained using the developed digital soil moisture meter as shown in Fig. 5 and a regression coefficient $\left(R^{2}\right)$ of 0.984 was obtained as shown in Fig. 5.

Table 2: Digital Soil Moisture Meter Readings and Moisture Contents of Soil Samples.

\begin{tabular}{cccc}
\hline S/N & $\begin{array}{c}\text { ml of } \\
\text { water }\end{array}$ & $\begin{array}{c}\text { Oven Dry } \\
\text { Moisture content } \\
(\%)\end{array}$ & $\begin{array}{c}\text { Digital soil } \\
\text { moisture meter } \\
(\%)\end{array}$ \\
\hline 1 & 0 & 0.0 & 3.0 \\
2 & 0.5 & 1.3 & 6.0 \\
3 & 1.0 & 1.8 & 10 \\
4 & 1.5 & 3.2 & 13 \\
5 & 2.0 & 3.9 & 15 \\
6 & 2.5 & 4.7 & 18 \\
7 & 3.0 & 5.4 & 21 \\
8 & 3.5 & 7.7 & 23 \\
9 & 4.0 & 9.1 & 26 \\
10 & 4.5 & 10.5 & 29 \\
11 & 5.0 & 11.9 & 33 \\
12 & 5.5 & 13.2 & 36 \\
13 & 6.0 & 14.6 & 40 \\
14 & 6.5 & 16.7 & 43 \\
15 & 7.0 & 19.3 & 46 \\
\hline
\end{tabular}

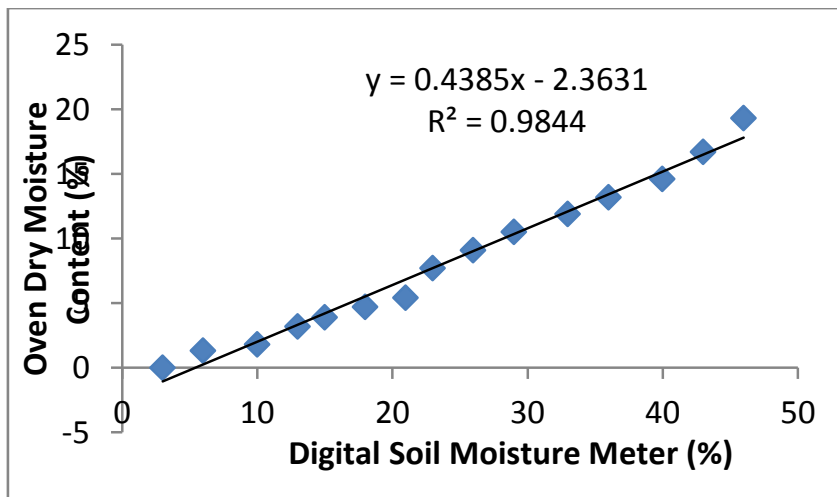

Fig. 5: Calibration Graph for the Digital Soil Moisture Meter 


\subsection{Validation of the Digital Soil Moisture Meter}

In order to validate the calibrated digital soil moisture meter, twenty (20) soil samples were collected randomly at depths of $20 \mathrm{~cm}, 20 \mathrm{~cm}$ apart from each other from the Agricultural and Bioresources Engineering experimental farm plot and taken to the laboratory for analysis. The calibrated digital soil moisture meter was used to determine the moisture content of the soil samples and the same samples were oven dried to determine the percentage moisture content of these samples. The results obtained from these measurements are shown in Table 3. The oven dry moisture content was plotted against the calibrated digital soil moisture meter and regression coefficient $\left(R^{2}\right)$ of 0.964 was obtained as shown in Fig. 6.

Table 3: Validation Results Obtained from Oven dry Measurement and the Digital Soil Moisture Meter Readings.

\begin{tabular}{cccc}
\hline S/N & Samples & $\begin{array}{c}\text { Oven dry moisture } \\
\text { content }(\%)\end{array}$ & $\begin{array}{c}\text { Digital soil moisture } \\
\text { meter }(\%)\end{array}$ \\
\hline 1 & A & 5.4 & 6 \\
2 & B & 6.6 & 9 \\
3 & C & 6.8 & 10 \\
4 & D & 7.2 & 11 \\
5 & E & 7.4 & 11 \\
6 & F & 7.8 & 12 \\
7 & G & 8.0 & 15 \\
8 & H & 8.8 & 16 \\
9 & I & 9.5 & 18 \\
10 & J & 9.8 & 19 \\
11 & K & 11.5 & 23 \\
12 & L & 11.6 & 23 \\
13 & M & 11.8 & 24 \\
14 & N & 12.0 & 26 \\
15 & O & 12.2 & 26 \\
16 & P & 12.4 & 27 \\
17 & $\mathrm{Q}$ & 12.6 & 29 \\
18 & $\mathrm{R}$ & 13.0 & 33 \\
19 & $\mathrm{~S}$ & 13.2 & 34 \\
20 & $\mathrm{~T}$ & 14.0 & 37 \\
\hline
\end{tabular}

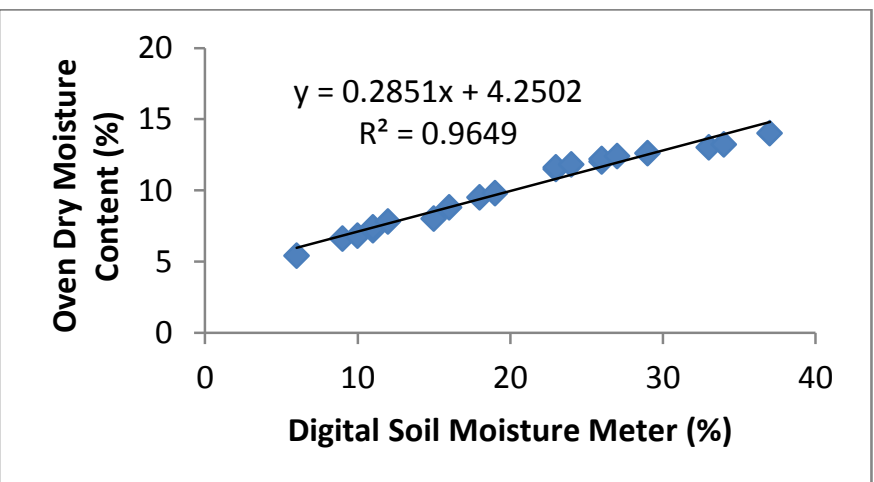

Fig. 6: Validation Graph for Digital Soil Moisture Meter

\subsection{Discussion}

Table 2 shows fifteen soil samples of moisture content at different level of water added to the soil sample. When the water is been added to the soil sample, the moisture in the soil increases by using both the moisture content process and digital soil moisture meter. The data collected was used to calibrate the digital soil moisture meter.

The graph in Fig. 5 shows the calibration graph of the percentage moisture content versus the digital soil moisture meter readings. From the graph, a linear regression coefficient was developed relating soil moisture content obtained to digital soil moisture meter readings. The coefficient value $\left(\mathrm{R}^{2}\right)$ for linear regression between the different levels of water added was 0.984 which is an acceptable value. According to the $\mathrm{R}^{2}$ value, a high correlation was observed between the moisture content and digital soil moisture meter.

From Table 3, the moisture content of the soils at the same depth at different points, there was variation in the moisture contents showing that the infiltration of water into the soil at the same depth varies. The data collected from oven dry were used to validate the calibrated digital soil moisture meter. The graph in Fig. 6 shows the validation graph of percentage measured moisture content versus the calibrated digital soil moisture meter readings. From the graph in Fig. 6, there was a correlation between the moisture content (oven dry) and the digital soil moisture meter with the regression value $\left(R^{2}\right)$ of 0.964 . This high $R^{2}$ value presented a vivid correlation between the digital soil moisture meter and moisture content. The developed meter provided up to $96 \%$ accuracy in estimating the value of the soil moisture content.

\section{CONCLUSION}

To determine when and the amount of water to be irrigated for crop production, the moisture content of the soil has to be determined. A digital soil moisture meter using the NE555 timer and micro controller as a major electronic component was developed and tested, which display its output in a range of 0.0 to $99 \%$ on the 7 -segment displayed unit.

The digital soil moisture meter developed was calibrated using gravimetric method of soil moisture determination. The results achieved revealed a relatively linear relationship between the moisture content process and the digital soil moisture meter. The regression coefficient $\left(R^{2}\right)$ of the digital soil moisture meter calibration was 0.984 . In order to validate the calibrated digital soil moisture meter, 
some soil samples were used to test and there was correlation between calibrated digital soil moisture meter and the tested samples (oven dry). The regression coefficient $\left(R^{2}\right)$ was found to be 0.964 , showing validity of the developed digital soil moisture meter. The developed meter provided up to $96 \%$ accuracy in estimating the value of the soil moisture content.

The results achieved showed that the developed digital soil moisture meter is more reliable, sensitive, precise and easy to use.

\section{REFERENCES}

[1] Asawa, G. L. Irrigation and water resources Engineering. New age international (P) limited, publishers, New Delhi, India, 2008.

[2] http://electronics.stackexchange.com/questions/9 455/soil-moisture-measurement. Accessed on 20/10/2015.

[3] Soltani, M. and Alimardani, R. Prediction of corn and lentil moisture content using dielectric properties. Journal of Agricultural Technology 7(5), 2011, pp1223-1232.
[4] Brendan, H. G. Comparison of techniques for measuring the water content of soil and other porous media. An Msc thesis submitted to the Department of Agricultural Chemistry \& Soil Science, University of Sydney, New South Wales, Australia, 1999.

[5] http://www.lemnatec.com/soil-water-content/ Accessed on 10/11/2015.

[6] http://www.ictinternational.com/casestudies/soilmoisture-measurement-instrumentation/ Accessed on $10 / 11 / 2015$.

[7] White, I. and Zegelin, S. J. Electric and dielectric methods for monitoring soil-water content. In: (eds. L.G. Wilson, L. G. Everett \& S. J. Cullen) Handbook of Vadose Zone Characterization and Monitoring. CRC Press, Boca Raton, 1995, pp343385.

[8] Whalley, W. R., Dean, T. J. and Izzard, P. Evaluation of the capacitance technique as a method for dynamically measuring soil water content. Journal of Agricultural Engineering Research, 52, 1992, pp147-155.

[9] Schmugge, T. J., Jackson, T. J. and Mickim, H. L. Survey Methods for Soil Moisture Determination. Water Resources. Res., 16, 1980, pp966-979. 